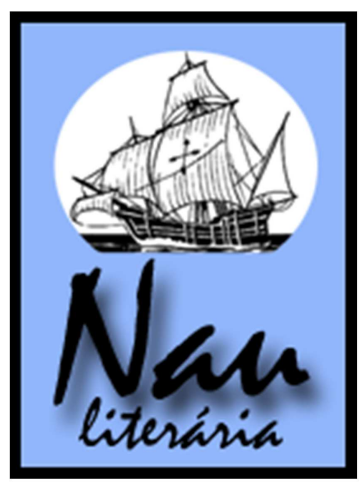

\title{
Signos Partidos: uma análise da (des)construção da subjetividade na narrativa de $O$ Quieto Animal da Esquina, de João Gilberto Noll
}

\begin{abstract}
Resumo: A partir das definições de pós-modernidade de autores como Stuart Hall (2006) e Nicolau Sevcenko (1988), busca-se analisar a novela $O$ quieto animal da esquina, de João Gilberto Noll, com foco no desmanche e na desconstrução. Para tanto, conceitos modernistas como flâneur e bildungsroman são apresentados e redefinidos de acordo com a proposta nolliana.
\end{abstract}

Palavras-chave: João Gilberto Noll, O quieto animal da esquina, pós-modernidade, desconstrução, romance de deformação.

\begin{abstract}
From the definitions of post-modernism, as definied by authors such as Stuart Hall (2006) ou Nicolau Sevcenko (1998), the goal of this work is to analyze the novel $O$ Quieto Animal da Esquina, by João Gilberto Noll, focusing on the chop and the deconstruction. Therefote, modern concepts as flâneur and bildungsroman are presented and redefined according to the novel's configuration.
\end{abstract}

Keywords: João Gilberto Noll, O Queito Animal da Esquina, post-modernism, deconstruction, bildungsroman.

O multiculturalismo é uma das principais marcas da pós-modernidade, possibilitandonos defini-la como a era da informação e da diversidade. Há, na contemporaneidade, um movimento ímpar de rompimento com o controle de produção e difusão da ciência e da arte, e de inclusão de grupos até então excluídos do circuito cultural principal. Como consequência, percebemos uma inovação nos padrões estéticos e temáticos que compõem a arte do começo do século XXI, tornando cada vez mais explícita sua relação com as lutas sociais e seu uso de maneira engajada e consciente.

A literatura, enquanto instituição sócio-cultural, está tendo sua função social totalmente reinventada na pós-modernidade, afinal, historicamente, seu papel na consolidação ou no desmoronamento das ideologias sempre foi central. Percebemos, desde os textos da Grécia Antiga, uma preocupação em incentivar textos literários em consonância com as crenças das elites, e um controle da literatura crítica - capaz de desestabilizar a ordem vigente. Dessa forma, era concedida à literatura a capacidade de influenciar a mentalidade de uma

\footnotetext{
*Formada em Letras - Licenciatura / Português e Letras - Licenciatura / Inglês pela UFMG. Mestranda em Literaturas de Língua Portuguesa pela Pontifícia Universidade Católica de Minas Gerais
} 
época, provocar a revolta ou educar a população de maneira mais eficiente que através de textos não-literários. Entretanto, na pós-modernidade, com a valorização do visual em detrimento do discursivo, percebe-se a valorização da arte imagética em detrimento da textual. Dessa forma, o fazer literário migrou da posição central para a margem, transformando a literatura em uma arte menos apreciada e consumida, mas, por outro lado, consideravelmente mais livre. Isso porque o olhar dominante sobre a literatura mudou, já que sua função moralizadora dissipou-se na pluralidade de manifestações artísticas e fez com que ela passasse a ocupar um espaço social menos demarcado, e, por isso mesmo, mais fluido.

Sendo assim, é possível perceber o caráter duplamente marginal da literatura pósmoderna: como manifestação cultural, ela está à margem do sistema, que, regido pelo consumo e pela funcionalidade, não encontra espaço para a fabulação. Já em seu interior, a literatura tem apresentado uma inovadora participação daquilo até então excluído ou considerado não-literário, incorporando novos temas, formas, estéticas e vozes. Dessa forma, ao perder seu espaço de elite no meio das artes, a literatura perdeu-se também das elites, assumindo um caráter transgressor, plurivocal e marginal que a define como manifestação cultural, e que também a caracteriza na análise textual.

É sobre ampliação desse tipo de literatura despreocupada de sua função de civilização, e engajada na narrativa da liberdade, que Ricardo Piglia fala no artigo "Una propuesta para el nuevo milenio" (2001). Segundo o autor, se a literatura é, como antes afirmara Roland Barthes (2007), o lugar do outro falar, ela deve empenhar-se em agir como "esse distanciamento, quase uma elipse, uma pequena tomada de distância a respeito do que está se tentando dizer, [que] é quase uma metáfora, alguém que fala por ele e expressa a dor de um modo sóbrio, direto e muito comovente.” (PIGLIA, 2001, p. 3) Dessa forma, a literatura deve afastar-se do centro, deixando que a linguagem "fale também da margem, daquele lugar em que se ouve, em que chega o outro." (PIGLIA, 2001, p. 10) Portanto, a literatura assume de forma consciente a força da projeção, da possibilidade de se perceber realidades outras, mesmo no interior de um sistema opressor e focado na utilidade. Mais uma vez, seu valor é concedido à capacidade humanizadora - não por educar e uniformizar a sociedade, mas, ao contrário, por inserir nela a liberdade.

Como consequência dessa mudança de paradigma, a crítica literária tem incorporado outras questões em suas análises. Rompendo com a tradição, através, principalmente, dos Estudos Culturais, o crítico literário assume, então, o papel de contextualizar e refletir sobre o lugar da obra, acrescentando à análise estética, a percepção da literatura como parte integrante e ativa do sistema social. Refletindo acerca da necessidade de se revisar o papel da crítica 
literária, Eneida de Souza afirma: "Aceitar esse desafio é uma das formas de continuar a mover o debate teórico, para que este não se transforme em consenso de grupos ou na apatia acadêmica, provocada por um certo tipo de mal-estar, que não incita a curiosidade, mas, ao contrário, alimenta o conservadorismo" (SOUZA, 1998, P.29).

Dessa forma, trabalhar com uma novela de João Gilberto Noll, é acatar o desafio proposto por Eneida de Souza e buscar na literatura brasileira uma obra que representa, na estética e na temática, as tendências da pós-modernidade. Assim, a escolha por Noll, um autor que discute e problematiza o lugar do sujeito na contemporaneidade, produzindo uma obra fragmentada ou porosa, mas, ao mesmo tempo, brutalmente reflexiva, é abraçar o projeto de buscar a margem - e sua movimentação constante - na literatura.

O Quieto Animal da Esquina (1991) é o sexto livro do autor e, na visão de alguns críticos, compõe uma trilogia com Hotel Atlântico (1989) e Harmada (1993). É possível ainda afirmar que não apenas os três, mas todos os livros de Noll - A Fúria do Corpo (1981), Bandoleiros (1985), Rastros do Verão (1986), A Céu Aberto (1996), Canoas e Marolas (1999), Berkeley em Bellaggio (2002), Mínimos, múltiplos, comuns (2003), A Máquina do Ser (2006), Acenos e Afagos (2008) e O Anjo das Ondas (2009) - tratam do mesmo protagonista, um homem abandonado e vazio, em constante movimento. Segundo Manuel da Costa Pinto, “em Noll, seja qual for o livro, o protagonista é invariavelmente um ser errante, para quem a vida familiar (no sentido amplo do termo) é uma forma de encarceramento e que, ao buscar exílio, encontra cárceres renovados" (PINTO, 2004, p. 95). Dessa forma, a principal marca do escritor é a narrativa da errância, do nomadismo, e dos aspectos cotidianos mínimos.

Em O Quieto Animal, fragmentação e pluralismo estão presentes nas contradições e angústias de seu protagonista-narrador. Sua escrita é um convite à reflexão, na medida em que busca romper com aspectos vários da tradição literária, como a onisciência do narrador (que é nesta obra absolutamente volátil), a organização textual em blocos interligados (a conexão entre as partes da novela precisa ser pensada pelo leitor) ou a presença de diferentes vozes marcada pela existência de diferentes personagens (pois aqui é o protagonista-narrador que incorpora pontos de vista opostos e desconexos, mostrando a pluralidade do indivíduo).

É relevante notar a semelhança entre a obra de Noll e a de outros autores e textos pósmodernistas brasileiros, como Bernardo de Carvalho, Dalton Trevisan ou Silviano Santiago. Em todos eles, a fragmentação é utilizada como técnica sintática e semântica, possibilitando o debate sobre a ressignificação do leitor na narrativa pós-moderna. Afinal, segundo Domício Proença Filho, o fragmentarismo literário se aproxima da montagem cinematográfica e exige que o leitor chegue à estruturação do conjunto ao associar as partes, a partir de traços 
semânticos comuns dispostos ao longo de uma narrativa lacunar e falha (PROENÇA FILHO, 1998, p. 43).

Entretanto, mais importante que construir sentidos, a obra de Noll é um convite para lidar com a desconstrução. Afinal, nesse constante jogo entre ser e não-ser, João Gilberto Noll desconstrói a ideia de uma essência subjetiva, capaz de caracterizar o homem e determinar seu caráter e sua relação com o mundo. Por isso, em sua nota para a re-edição de $O$ quieto animal da esquina em 2003, Manuel da Costa Pinto afirma que a literatura de João Gilberto Noll é um "romance de deformação", em contraposição ao Bildungsroman, ou romance de formação.

Datando do século XIX, o termo Bildungsroman é formado pela combinação das palavras educação (bildungs) e romance. O livro do alemão Johann Goethe, Os anos de aprendizado de Wilhelm Meister, é tido como o principal exemplar do gênero, pois mantém, ao longo da narrativa, o foco na trajetória de seu protagonista, da juventude à vida adulta. $\mathrm{O}$ crítico alemão Oskar Morgenstern, ao comparar a epopeia e o romance, afirma que na primeira há uma descrição da influência do protagonista no espaço, ou seja, os efeitos exteriores causados por seus atos. Já no romance, o protagonista é transformado pelo exterior, fazendo com que o ambiente defina, gradativamente, seu caráter. (MORGENSTERN, apud MAAS, 2005, p. 1)

No Brasil, a escrita de romances de formação marcou a literatura dos séculos XIX e XX. Autores como José de Alencar, Raul Pompeia ou Jorge Amado fundamentaram a construção narrativa de seus romances na relação do protagonista com o meio, ao longo de sua juventude. Entretanto, diferenças consideráveis marcam a análise comparativa das obras destes autores. Se no século XIX o romance de formação, mantinha a ideia de acompanhar os atos heróicos e exemplares de seu protagonista, o século XX observou um afastamento da ideia de heroísmo que cedeu lugar à crítica e análise do homem comum. Bakhtin, discutindo o desenvolvimento do romance de formação, afirma que em práticas mais recentes,

a evolução do homem é indissolúvel da evolução histórica. A formação do homem efetua-se no tempo histórico real, necessário, com seu futuro,com seu caráter profundamente cronotópico. $\mathrm{O}$ homem se forma ao mesmo tempo em que o mundo, reflete em si mesmo a formação história do mundo. Ele é obrigado a transformar-se em um novo tipo de homem, ainda inédito. A imagem do homem perde seu caráter privado e desemboca na esfera espaçosa da existência histórica (BAKHTIN apud MAAS, 2005, p. 4).

Dessa forma, como afirma Bakhtin, o romance de formação passou a ser espaço de crítica social, percebendo que a formação do homem se faz em relação com o espaço histórico-social que ele habita. Assim, o romance de formação acompanhou a evolução da Modernidade: da 
utopia heróica da descoberta e da colonização à reflexão crítica sobre o espaço público e as divisões sociais.

Na escrita pós-moderna da novela de João Gilberto Noll, podemos perceber algumas ações típicas do romance de formação - como a transição da personagem para a vida adulta ou narração de seu percurso (viagens, andanças), a fim de apresentar a origem de seu conhecimento e seu caráter. Entretanto, é nítido o caráter irônico empregado pelo autor, que, ao se aproximar de tal gênero, desconstrói seus valores e representações simbólicas. Percebemos, que embora em movimento, o protagonista de $O$ quieto animal da esquina não tem destino, caminhando perdido e sem se sentir responsável por seu futuro. Assim, ele chega à vida adulta sem nenhum enobrecimento, sentindo-se ainda despreparado para assumir responsabilidade sobre seu destino - anseio condensado no jargão sempre repetido "sou um homem e não estou apaixonado".

Dessa forma, o autor se apropria do estilo literário a fim de mostrar suas lacunas e distorções. Segundo Érika Vieira:

a apropriação (...) é um termo que denota uma relação intertextual menos explícita, mas mais questionadora, hostil, ou até mesmo de caráter mais subversivo devido, principalmente, à postura crítica que adota. Enquanto a adaptação presta uma homenagem, a apropriação desafia o texto fonte, evocando, assim, uma ruptura com a tradição, seus valores e hierarquia. (VIEIRA, 2008, p. 5)

Noll, ao se apropriar das ideias do "romance de formação", redefine o conceito de sujeito e questiona preceitos como o valor humanizador da viagem ou a divisão maniqueísta das personagens. Isso porque, ao apagar as conquistas de uma personagem com trajetória semelhante às demais, o autor transforma o olhar lançado a ela e permite aos leitores refletir sobre as ideologias apresentadas por seus predecessores.

Além disso, a deformação do sujeito inclui também a deformação do conceito de nação. Conforme aponta Ivete Walty, "a inserção de um espaço no outro, de um tempo no outro, de uma personagem na outra, como fragmentos que se misturam sem remeter-se ao todo, são as ruínas de uma identidade textual e nacional, como o "Samba em Berlim" ou a "cachaça com coca-cola." (WALTY, 1998, p. 112). Por isso, a novela apresenta as fronteiras rompidas na pós-modernidade e mostra como a deformação dos espaços sociais - como a família ou a nação - reflete-se na fragmentação da subjetividade.

Para abordar a fragmentação de instituições várias, Noll concentra a narrativa na caminhada da personagem. Dessa forma, o narrador é capaz de produzir seu relato do interior de diferentes espaços, como a prisão, a cidade, o campo ou a fazenda. Além disso, tal 
estratégia faz com que sua instabilidade misture-se à fragilidade dos espaços que habita, já que todos se apresentam móveis, flácidos, ocupados.

Assim como o conceito de romance de formação, podemos perceber, ao abordarmos a movimentação do protagonista pelo romance, o esvaziamento da ideia de flâneur. O termo foi cunhado por Charles Baudelaire para tratar da tendência urbana moderna de andar pela cidade, possibilitando o encontro e a troca de experiências entre sujeitos diferentes. Seu uso costuma estar associado a um paradoxo, pois ao mesmo tempo em que reconhece o outro e a construção de uma memória social coletiva, ele inclui a percepção desdenhosa que as classes mais abastadas têm das mais pobres, marcando, assim, a reprodução de experiências e ideologias. Dessa forma, o flâneur é usado para representar não apenas a movimentação geográfica do homem moderno, mas também a consciência coletiva que os caracterizava.

Em Noll, a andança do protagonista pela cidade traz uma ideia oposta a esta postulada por Baudelaire, pois marca a ausência de convívio social e até mesmo de consciência coletiva e demonstrando, que embora habitem o mesmo espaço - mesmo quando esse é o espaço da casa -, os homens pós-modernos nada compartilham. Segundo Idelber Avelar: "o incômodo produzido pelos textos de Noll - a impressão de que tudo está em fluxo mas nada muda, já que a experiência nunca se converte em saber narrável - remete ao deslocamento que impõe a ficção de Noll à tradição moderna e baudelaireana do flâneur.” (AVELAR, 1999, p. 39)

Dessa forma, o vazio dos personagens de Noll é devido à falta de experiências vividas, em uma releitura às avessas do termo francês. Perdidos, incapazes de construir suas próprias memórias, eles também não podem se apoderar das memórias alheias, pois são incapazes de construir as relações sociais necessárias para enxergar o outro em si. Por isso, não compartilham das memórias coletivas nem a substituem por outras, vivendo sempre em movimento, mas fadados a só reconhecer o aqui e o agora. O exercício de leitura de Noll nos remete, pois, à falta de experiência, ao desapego de todos os valores sócio-culturais que carregamos para que possamos perceber a margem como o espaço errante, do indivíduo terrivelmente solitário.

Sendo assim, uma característica marcante do autor é dar mobilidade ao marginalizado - e também à margem. A constante movimentação da personagem ilustra a ausência de um espaço geográfico demarcado para a exclusão. Na verdade, seu deslocamento sem o objetivo de chegar a um lugar específico fortalece a ideia de um espaço fluido, mesmo que opressor, e se aproxima do conceito de errância postulado por Rachel Bouvet. Segundo a autora, o errante, ao contrário do nômade, não tem a ideia de percurso, ignorando o destino de sua 
caminhada. Dessa forma, ele segue em busca de outra coisa que não o trajeto em si e se orienta pelo desconhecido, pela falta. (BOUVET, 2006)

Portanto, em Noll, a solidão se coloca no centro das relações humanas, e se estende, inclusive, para aquelas entre leitor e texto. A ausência de diálogos, o vazio das experiências, a falta de lógica e estrutura no enredo: tudo isso nos leva a repensar o espaço do homem no mundo e o que o define como sujeito. Assim, a narrativa de $O$ quieto animal da esquina faz muito mais que apresentar um panorama das relações humanas deterioradas, ela nos mostra o individualismo em um nível que impossibilita aos homens perceber semelhanças entre si. Por isso, embora o protagonista caminhe em busca de pares - "existia um guri com minha cara por aí, um guri que se quisesse poderia mais tarde até se passar por mim” - a inexistência de laços ou semelhanças capaz de uni-lo a outro é sempre o que vem à tona.

Dessa forma, podemos analisar também a relação do protagonista com as questões políticas ou sociais que acontecem em seu entorno. Afinal, em todos eles (comícios políticos, chegada da polícia, Movimento dos Sem-terra), fica evidente o distanciamento, a falta de ideologias, o não-pertencimento a grupo algum. Além disso, as cenas de estupro - de Mariana e Gerda - são fundamentais para analisar a relação do protagonista com o ato sexual, seu desejo de se impor, de tornar-se o dominante.

Mais ainda, é fundamental discutir quais estratégias textuais foram usadas para que a História contemporânea fosse narrada a partir da ótica do indivíduo, das miudezas, afastada da grandiosidade das ideologias e insitituições modernas, e associada às curtas narrativas e ausências da pós-modernidade. Dessa forma, a aproximação do protagonista com os outros presos se dá pelo escatológico, a relação entre países colonizadores e colonizados se reduz ao relacionamento de pais e filho, ainda esse desconstruído, e o sexo é mostrado como instrumento na busca por si, e não pelo outro.

$\mathrm{Na}$ relação do protagonista com a instituição familiar em esfacelamento, é possível perceber como errância e vazio se apresentam como marcas coletivas de um sistema corrompido. Primeiramente, há a relação entre ele, sua mãe biológica e o pai ausente. Ao retornar para casa, um prédio ocupado no subúrbio de Porto Alegre, o protagonista se lembra da mãe: "aquela mulher que só parecia me esperar, desde que meu pai sumira, ela ali, sem mais nada a fazer que me esperar." (NOLL, 2003, p.10) A partir desse trecho, é possível perceber que o triângulo anteriormente formado entre o pai, a mãe e ele, foi rompido pela fuga do pai. A partir de então, o narrador julga ter a mãe só para si, a mulher submissa, que está sempre esperando por seu retorno. Dessa forma, ele se coloca no lugar do pai, 
acreditando não apenas que a mãe é sua mulher, mas também que seu desejo maior é o retorno do filho, e não o do marido que partira.

Dessa forma, a relação familiar já começa mutilada, pautada na ausência e na esperança do retorno. Entretanto, ela fica muito mais fragmentada quando a mãe afirma que está indo embora, rompendo com a ilusão do filho de que ela era sua mulher. A reação do filho à decisão da mãe é, na verdade, o que desencadeia todos os outros eventos da narrativa, pois é a partir daí que o protagonista se afasta de sua rotina de andarilho no centro de Porto Alegre.

Afinal, após a conversa com a mãe, ele vai para a parte térrea do prédio: "descia as escadas pensando nela", afirma. É nesse momento que vê sua vizinha, uma menina ainda mais nova que ele, sozinha. A cena de estupro que então acontece reflete sua crença de que, para ser sujeito, é preciso anular o outro: "agora já era tarde demais, eu precisava sufocar aquele grito. Quando meu pau entrou gozei, e o rumor surdo, o grito que eu sufocava esmagando a minha boca contra a dela, cessou." Dessa forma, seu prazer vem do silenciamento imposto, o gozo é uma resposta à anulação do outro, ao uso da força para fazer calar.

De forma semelhante, a narrativa apresenta o esfacelamento do Estado e das ideologias nacionalistas que marcaram a Modernidade. As personagens mais velhas aparecem como exemplares de um sistema em colapso: os alemães tentando manter seu papel de donos da terra, colonizadores; Otávio, ex-pracinha, que insiste em usar a boina da FEB; os policiais que, ao interrogar o protagonista, buscam a origem/essência de suas atitudes. Entretanto, todos são constantemente expulsos de seu espaço, ineficientes na tentativa de reproduzir um esquema já decadente

Além de tudo isso, as ideias de tempo e espaço narrativos também são problematizadas por Noll. Há uma fragmentação dos dois conceitos, que acaba por marcar a instantaneidade como sintoma dos tempos pós-modernos. O tempo é estranho ao narrador, pois acelera enquanto ele permanece o mesmo - "sou um homem e não estou apaixonado", diz ao se sentir atropelado pelas mudanças de seu corpo. Há ainda uma relação conflituosa entre presente e passado, como se o personagem acreditasse não ser mais o mesmo que fora: "daqui a pouco não precisarei mais mover uma palha para evitar o meu passado" (NOLL, 2003, p.58).

Da mesma forma, o espaço é sempre reduzido, ocupado, tomado. O prédio onde mora com a mãe, suas andanças pela Porto Alegre do erotismo e da sujeira, a cela dividida na prisão, o quarto minúsculo da clínica, a casa de Kurt: todos são metáforas para a margem, para o não-lugar do protagonista. 
Em todos esses exemplos, é clara a relação entre a escrita de Noll e os preceitos da pós-modernidade. Stuart Hall, em sua obra Identidades Culturais na Pós-modernidade, afirma que há uma angústia recorrente na contemporaneidade causada pelo colapso de algumas instituições e o questionamento de nossa subjetividade. Segundo o autor, há, na pósmodernidade, um "duplo deslocamento - descentração dos indivíduos tanto de seu lugar no mundo social e cultural quanto de si mesmos", ou seja, com o esfacelamento das concepções de fronteiras, etnias ou raças, o sujeito perde a percepção de sua subjetividade, e torna-se incapaz de assumir um lugar na dinâmica social. (HALL, 2006.)

Segundo Nicolau Sevcenko, a pós-modernidade, como resposta à crise das instituições grandiosas, se apresenta como um castelo de areia: "frágil, inconsistente, provisório, tal como todo ser humano. Um enigma que não merece a violência de ser decifrado." (SEVCENKO, 1988. P. 45). Dessa forma, negando a crença histórica de que existe algo maior que o homem, como, por exemplo, a nação ou a religião, a pós-modernidade volta-se para o sujeito, para a brevidade. Entretanto, esse sujeito também é frágil, incompleto por não reconhecer uma essência humanizadora em si mesmo e, portanto, incapaz de assumir o centro das relações sociais. A sociologia contemporânea é, assim, a ciência da lacuna, da falta de respostas.

Também, a literatura pós-moderna, em consonância com essa visão mutilada da subjetividade, se faz de migalhas e questionamentos, abandonando a ilusão de sentido do texto - ou sentido da vida - e assumindo a descrença e a impotência como patamares narrativos.

\section{Referências}

AVELAR, Idelber. João Gilberto Noll e o fim da viagem. Travessia, revista de literatura, n.31. Florianópolis, 1999.

BAHKTIN, Mikhail apud MAAS, W. P. M. D. O romance de formação (Bildungsroman) no Brasil. Modos de apropriação. Caminhos do Romance. 2005. Disponível em <http://www.caminhosdoromance.iel.unicamp.br>. Acesso em: 05/02/2012.

BARTHES, Roland. Crítica e verdade. São Paulo: Perspectiva, 2007.

BOUVET, Rachel. Du parcours nomade à l'errance: une figure de l'entre-deux.In: BOUVET, R.; CARPENTIER, A. e CHARTIER, D. (dir.). Nomades, voyageurs, explorateurs, déambulateurs. Paris: L'Harmattan, 2006. 
CONNOR, Steven. Cultura pós-moderna: Introdução às Teorias do Contemporâneo. São Paulo : Loyola, 1993.

HALL, Stuart. Identidades Culturais na Pós-modernidade. Rio de Janeiro: DP\&A. 2006.

JAMESON, Frederic. Pós modernidade e sociedade de consumo. In: Novos Estudos CEBRAP, n. 12. São Paulo, 1985.

MORGENSTERN, Oskar apud MAAS, W. P. M. D. O romance de formação (Bildungsroman) no Brasil. Modos de apropriação. Caminhos do Romance. 2005. Disponível em <http://www.caminhosdoromance.iel.unicamp.br>. Acesso em: 05/03/2012.

NOLL, João Gilberto. O quieto animal da esquina. Brasília: Francis, 2003.

PINTO, Manuel da Costa. Orelha. In: NOLL, João Gilberto. O Quieto Animal da Esquina. Brasília: Francis, 2003.

PINTO, Manuel da Costa. Literatura Brasileira Hoje. São Paulo: Publifolha, 2004.

SEVCENKO, Nicolau. O enigma do pós-moderno. In: Pós modernidade. São Paulo: Editora Roberto Cardoso de Oliveira. 1988.

VIEIRA, Érika Viviane Costa. Das apropriações literárias: algumas considerações a respeito da leitura e do suplemento de Derrida. http://www.letras.ufmg.br/poslit/08_publicacoes_pgs/Em\%20Tese\%2016/16\%203/erikav iviane.pdf. Acessado em 11/02/2012.

SOUZA, Eneida de. A teoria em crise. In: Revista Brasileira de Literatura Comparada. Florianópolis, 1998.

WALTY, Ivete. Iracema, Macunaíma e O quieto animal da esquina: O nacional em imagens e borrões. In: Travessia, revista de literatura, n. 37. Florianopólis, 1998. 